\title{
El Museo de la Evolución Humana de Burgos, una caja de luz para reflexionar sobre la evolución
}

Lo primero que sorprende al divisar el Museo de la Evolución Humana (MEH) es su volumen y transparencia; una vez dentro esa sensación se acentúa. Su diseño moderno y atrevido se conforma en un volumen cuadrado a modo de caja de luz, transparente y reflectante al mismo tiempo, que ocupa un lugar estratégico en una de las márgenes del río Arlanzón a su paso por Burgos. EI MEH es concebido como la cabecera del Sistema Atapuerca, Cultura de la Evolución, figura de gestión que aúna objetivos culturales, sociales y económicos en un Espacio Cultural.

El Museo de la Evolución Humana es un proyecto de la Consejería de Cultura de la Junta de Castilla y León que lo concibió como un centro museístico de enfoque interdisciplinar para generar y difundir el conocimiento relativo a las relaciones entre la evolución en el pasado, el presente y en el futuro, y la investigación en el campo de la evolución humana. Al mismo tiempo el MEH es la cabecera del Sistema Atapuerca, Cultura de la Evolución, figura de gestión que aúna objetivos culturales, sociales y económicos en un Espacio Cultural, en base a dos ejes patrimoniales excepcionales: el MEH, espacio cultural y divulgativo sobre el origen y evolución de nuestra especie; y la Sierra de Atapuerca, territorio científico único de extraordinarios descubrimientos arqueológicos y paleontológicos, y espacio de gran interés geográfico, paisajístico y natural.

Se trata de un museo de última generación, en que los recursos y la efectividad han sido empleados de forma acorde. En cuanto a la arquitectura, por ejemplo, ofrece en su interior un alarde constructivo, un gigantesco vano vacío de columnas y elementos arquitectónicos: un techo colgado, sostenido por unas fuertes estructuras laterales en forma de aspa y pintadas en rojo. Pero también en lo relativo a criterios y recursos museográfi$\cos$, ya que resulta un paradigma hiper-

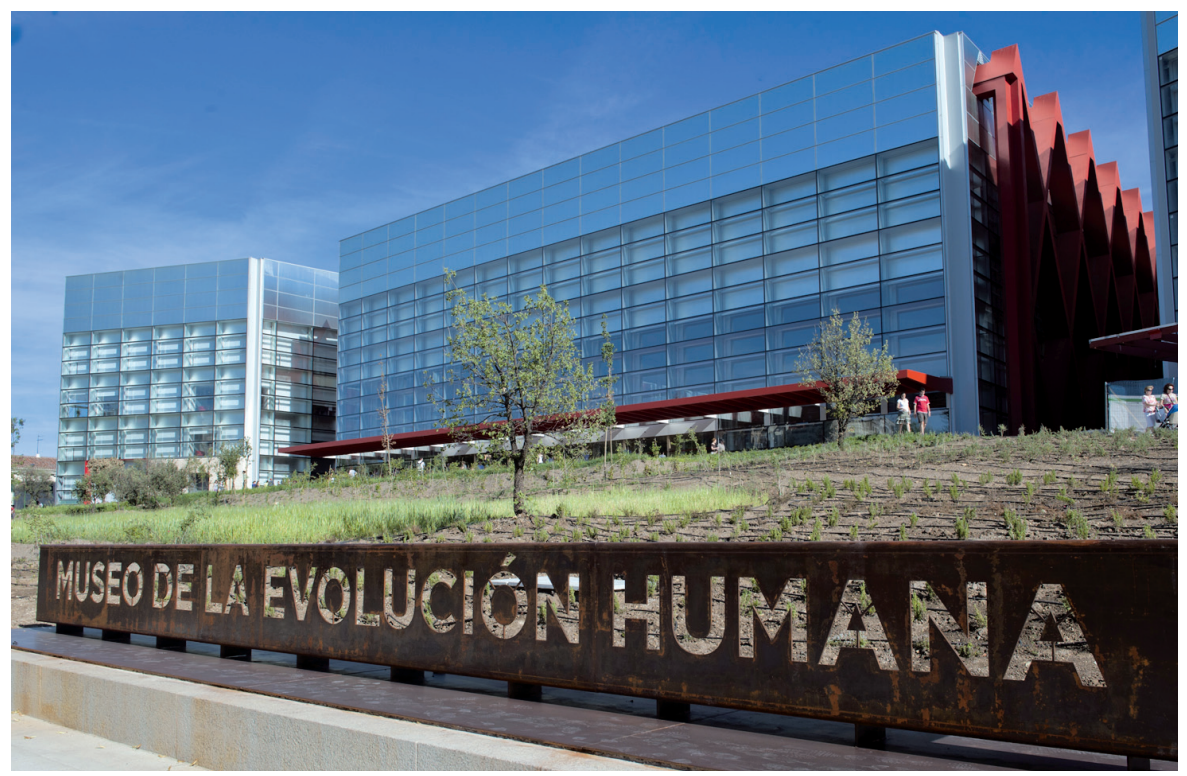

Vista exterior diurna. Fuente: Archivo del Museo de la Evolución Humana

media en el que elementos expositivos tradicionales se combinan con las ricas posibilidades que facilitan las nuevas tecnologias: interactivos, audiovisuales e instalaciones interactúan con el visitante a nivel de sensaciones, propiciando la participación y favoreciendo la comprensión de los contenidos.

\section{El proyecto}

La idea de un Museo de la Evolución Humana en Burgos surgió hace una década, cuando los yacimientos de la Sierra de Atapuerca fueron declarados Patrimonio Mundial por la UNESCO. El Ayuntamiento de Burgos potenció esta iniciativa y solicitó la intervención de la Comunidad Autónoma, consciente de que este ambicioso proyecto tenía que tener una calidad y envergadura pareja a la de los yacimientos, además de un carácter que sobrepasara los límites locales.

En 2005 Juan Navarro Baldeweg gana el concurso, con un proyecto de claro compromiso formal con la naturaleza, la arqueología y el paisaje, elementos que se evocan en la organización de los volúmenes y en la trasparencia de su estructura.

El proyecto de museografía y museología fue redactado por la empresa MBD, que asumió el reto de traducir el conocimiento experto y técnico sobre evolución humana a un saber riguroso pero popular y accesible, sin renunciar a tratar el discurso de forma atractiva y lúdica, enlazando los aspectos culturales con los de ocio formativo y un recorrido impactante y emocionante, pero también abarcable y participativo.

La ejecución del proyecto fue adjudicada a la UTE Empty-Sono, empresa encargada de hacer realidad y adecuar espacialmente el proyecto teórico.

\section{El contenedor}

El Museo es un prisma de $60 \mathrm{~m}$ de frente, 30 de altura y 90 de fondo. Una doble piel 


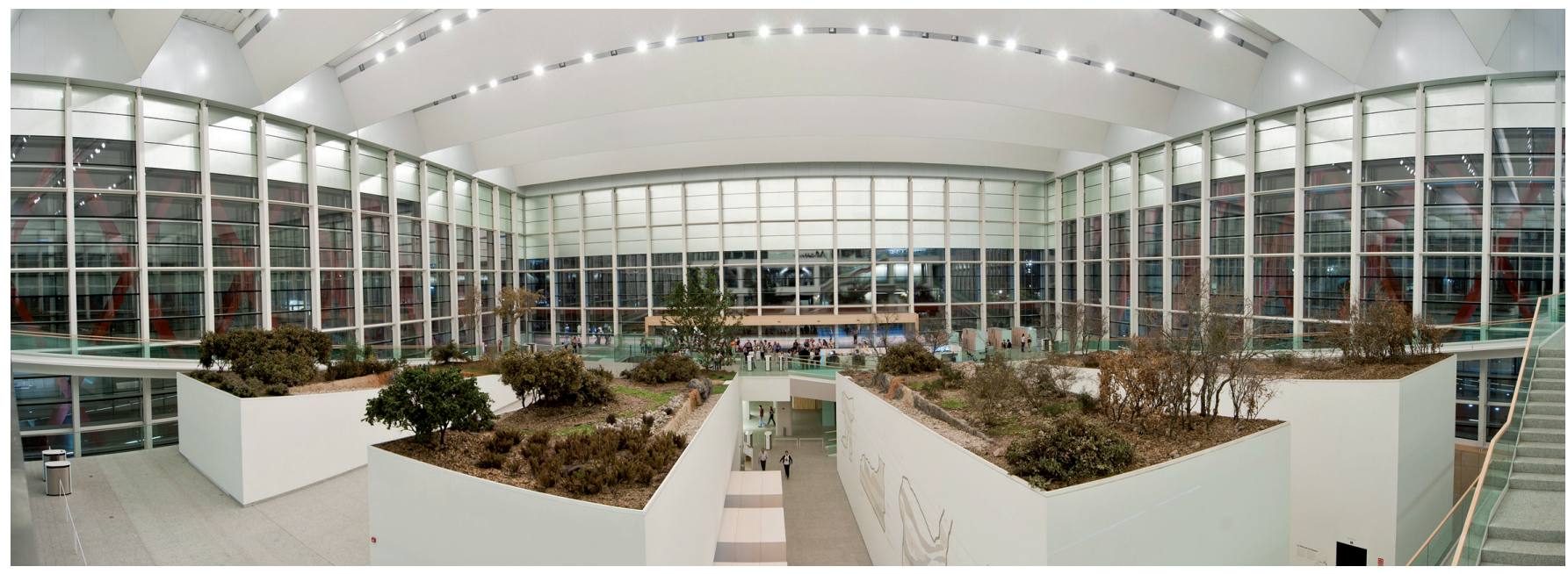

Visión panorámica interior, paisajismo y Atapuerca. Fuente: Archivo del Museo de la Evolución Humana

de vidrio forma las cuatro fachadas y la cubierta permite la luz cenital, dotando al espacio de una acusada luminosidad y facilitando su eficiencia energética.

En el interior, consta de dos áreas funcionales diferenciadas: el área de la exposición permanente $\left(6.000 \mathrm{~m}^{2}\right.$, con una media de $1.500 \mathrm{~m}^{2}$ por planta) y el área cultural de uso público $\left(2.000 \mathrm{~m}^{2}\right)$, lo que junto a zonas complementarias de servicios e instalaciones suponen una superficie total de $12.000 \mathrm{~m}^{2}$

\section{Los contenidos}

Paisajismo. En el proyecto la naturaleza -como archivo de todo el conocimiento de la trayectoria en la tierra de los seres vivos- cobra un protagonismo destacado que se manifiesta en la importancia del jardin exterior y el paisajismo interior.

La zona de acceso recrea el paisaje circundante a la Sierra de Atapuerca y su relación con el río Arlanzón, río que transita cerca del MEH y de la propia Sierra. La protagonista es la vegetación que vemos actualmente en la Sierra: campos de cereal (trigo y cebada), robles y encinas rodados de diversas plantas y arbustos (brezo, lavanda, tomillo, rosal silvestre, etc.).

El paisajismo interior muestra el cambio del paisaje de la Sierra a lo largo del último millón de años. Para ello se ha construido un paisaje preservado articulado en cuatro espacios que recrean la vegetación de la Sierra hace 800.000, $600.000,350.000$ y 50.000 años. Ante la imposibilidad de introducir vegetación natural, se han utilizado ejemplares preservados, buena parte de ellos procedentes de la propia Sierra, al igual que el lugar concreto cuyo paisaje se documentó fotográficamente y se reproduce en 4 fragmentos correspondientes a cuatro periodos y estaciones diferentes.

\section{Debe ser un centro apto para} imaginar, sentir y reflexionar sobre el ser humano (...) pero también sobre la importancia de la naturaleza que nos

\section{ha ayudado en este camino} evolutivo y a la que, cada día más, estamos dando la espalda

La Planta -1, o corazón del Museo, resulta un lugar idóneo para presentar los yacimientos de la Sierra de Atapuerca y que el visitante pueda comprender su importancia en el marco de la evolución humana, y cómo se desarrollan los trabajos, durante la excavación, el lavado, el laboratorio y el estudio posterior por los especialistas de las más de 30 disciplinas que intervienen en este proyecto de investigación. Bajo los módulos del paisaje se exhiben los fósiles originales más emblemáticos de Homo antecessor y Homo heidelbergensis, así como su industria y la fauna con la que convivían. También hay un apartado para hablar de la historia de los descubrimientos y de la trayectoria divulgativa y científica del equipo de investigaciones de Atapuerca.

La planta 0 se destina a plantear la evolución en términos biológicos, y explica cómo a lo largo de la historia del planeta las diferentes especies han ido evolucionando. El recorrido comienza con la figura de Charles Darwin y la importancia que tuvo su Teoría de la Evolución basada en el mecanismo de la selección natural. El ámbito articulado en torno a la anatomía comparada nos anima a comprobar que compartimos rasgos anatómicos con animales tan dispares como los murciélagos o los cocodrilos. La Galería de los Homínidos, única en su género y en su tratamiento en el contexto museográfico internacional, hace un recorrido a través de las reproducciones (obras excelentes de E. Daynès) de las especies fósiles que han protagonizado el proceso de hominización. El último ámbito profundiza, en torno a la figura de Ramón y Cajal, sobre el cerebro, órgano vital en el proceso evolutivo. 


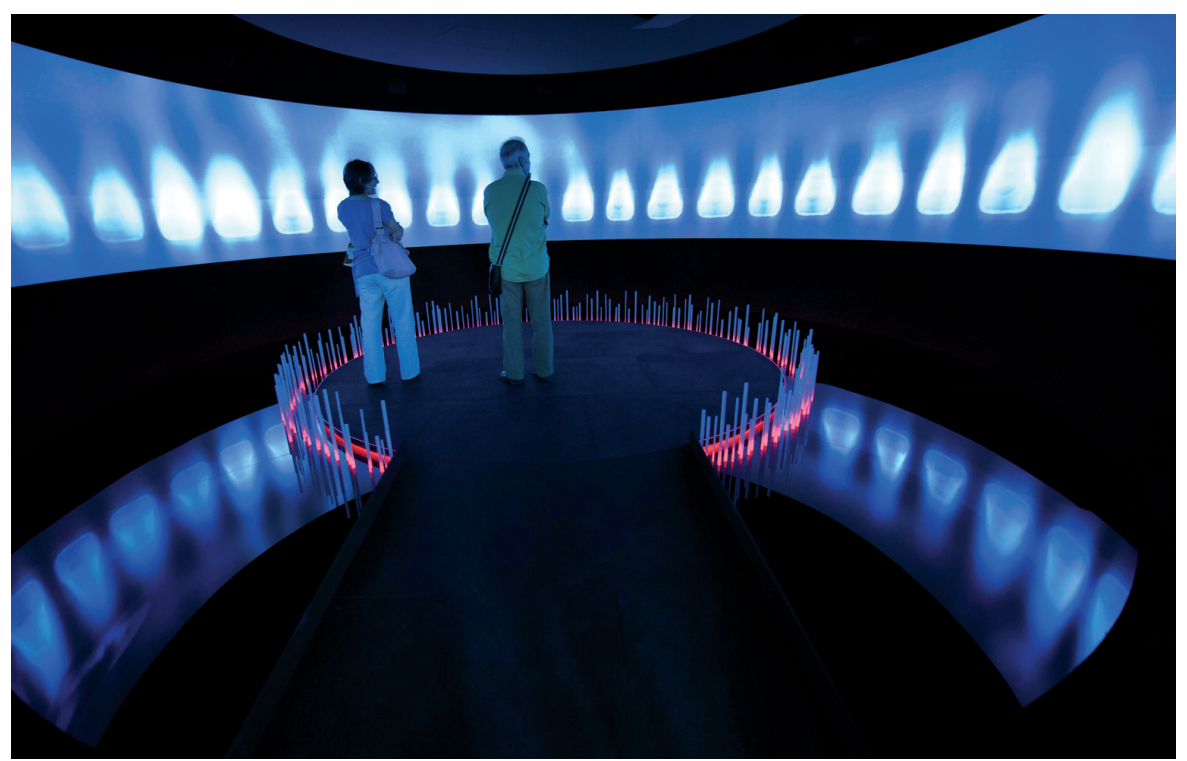

Audiovisual envolvente sobre el fuego. Planta 1 Evolución Cultural. Fuente: Archivo del Museo de la Evolución Humana

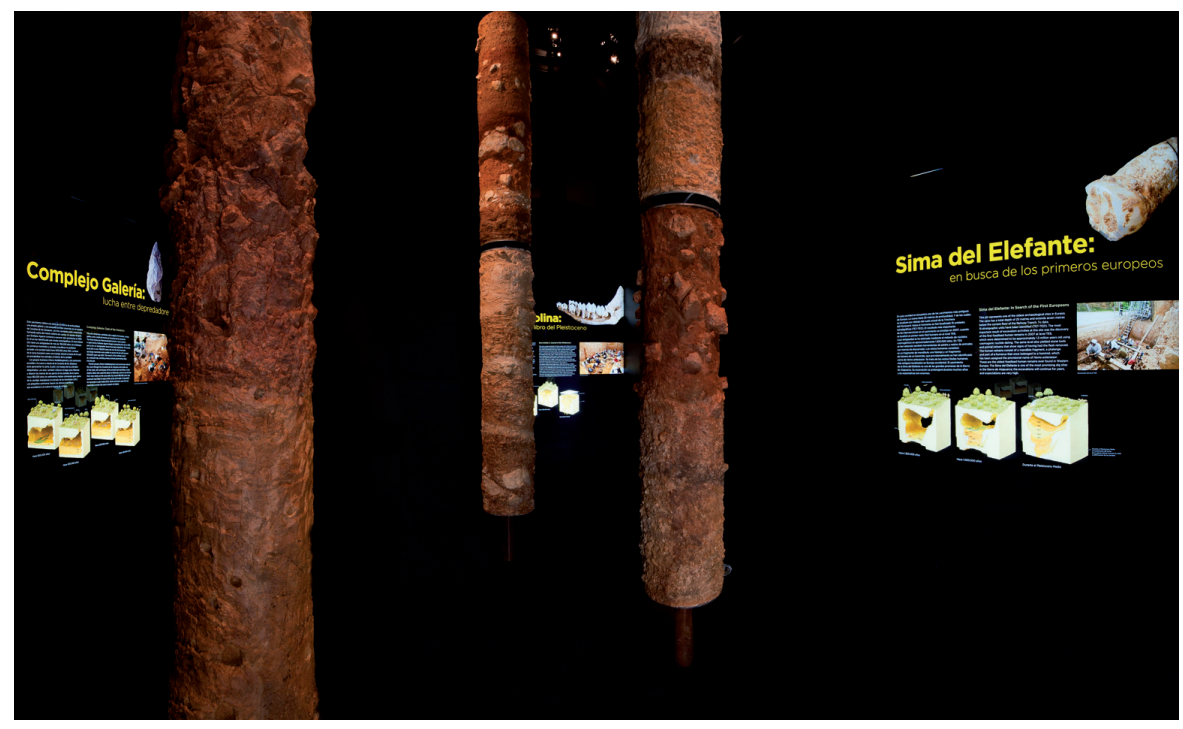

Yacimientos de Atapuerca. Planta -1 Sierra de Atapuerca. Fuente: Archivo del Museo de la Evolución Humana

La planta 1 trasmite la evolución cultural y explica la herencia cultural, la función simbólica, la significación y el manejo de los signos y el lenguaje, la capacidad de gesto funcional... No se trata de exponer hitos estáticos de nuestra civilización, sino de describir la evolución de aquellas manifestaciones que identifican a los grupos humanos. Comienza presentando dos grandes avances de los grupos cazadores-recolectores: la manufactura de útiles y el descubrimiento y dominio del fuego, que se puede percibir en el centro de una proyección envolvente. de las formas de vida de los neandertales y sapiens utilizando dioramas de sus campamentos y enterramientos, como paso para hablar del mundo simbólico, de las creencias y de las manifestaciones artísticas. El último ámbito se dedica a los primeros pastores y agricultores, evidenciando la importancia de la revolución neolítica.

La planta 2 transmite la importancia de los ecosistemas en el devenir humano. Un audiovisual permite conocer y sentir tres de los medios que más influyeron: la selva tropical en la que se originaron los
Debe ser un centro vivo apto para imaginar, sentir y reflexionar sobre el ser humano

homínidos; la sabana que les abasteció de carne para que el cerebro creciera; y la tundra-taiga, conquistada gracias a la adaptación a ambientes extremos.

\section{Los retos}

El MEH es un museo único en su género y en su temática. No es un museo arqueológico paleontológico al uso, tampoco un museo de ciencias naturales, ni un parque temático, ni un museo de la ciencia. Debe ser, y en ello estamos empeñados, un centro vivo apto para imaginar, sentir y reflexionar sobre el ser humano -nosotros-, su evolución, la trascendencia de los cambios biológicos y de los avances tecnológicos y culturales, pero también sobre la importancia de los ecosistemas que nos han ido dando cobijo, de la naturaleza que nos ha ayudado en este camino evolutivo y a la que, cada día más, estamos dando la espalda.

Este proyecto singular pretende convertirse en una institución líder a nivel nacional e internacional, en un referente científico respecto al tratamiento de la cultura material e inmaterial asociada y de la difusión de la temática concreta. A ello debe contribuir, y en igual medida, la espectacularidad del edificio; la temática, compleja pero atractiva para una gran parte de la población; la capacidad de atraer y atrapar la atención del visitante tanto del montaje museográfico como de los programas didácticos y dinamizadores que desde el MEH se programen; la calidad y calidez en cuanto a la atención del visitante por parte del equipo humano que trabaja en el MEH y, de manera especial, la colaboración y participación del público.

\section{Aurora Martín Nájera}

Museo de la Evolución Humana

Coordinadora General 